2010-04-01

\title{
A Raman Spectroscopy Study of the Solubilisation of SWCNTS by POlycyclic Aromatic Hydrocarbons
}

\author{
Sourabhi Debnath \\ Technological University Dublin, Sourabhi.debnath@tudublin.ie \\ Qiaohuan Cheng \\ Technological University Dublin, qiaohuan.cheng@tudublin.ie \\ Theresa Hedderman \\ Technological University Dublin, Theresa.Hedderman@tudublin.ie
}

See next page for additional authors

Follow this and additional works at: https://arrow.tudublin.ie/nanolart

Part of the Physics Commons

\section{Recommended Citation}

Debnath, S. et al (2010) A Raman Spectroscopy Study of the Solubilisation of SWCNTS by Polycyclic Aromatic Hydrocarbons. Carbon, Vol.48, no. 5, pp.1489-1497. http://www.sciencedirect.com/science/ journal/00086223. doi:10.1016/j.carbon.2009.12.044

This Article is brought to you for free and open access by the NanoLab at ARROW@TU Dublin. It has been accepted for inclusion in Articles by an authorized administrator of ARROW@TU Dublin. For more information, please contact arrow.admin@tudublin.ie, aisling.coyne@tudublin.ie,gerard.connolly@tudublin.ie. Funder: Science Foundation Ireland

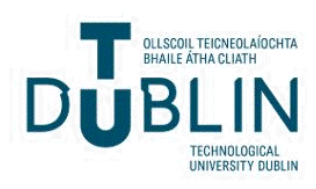




\section{Authors}

Sourabhi Debnath, Qiaohuan Cheng, Theresa Hedderman, and Hugh Byrne 


\title{
A Raman spectroscopy study of the solubilisation of SWCNTs by polycyclic aromatic hydrocarbons
}

\author{
Sourabhi Debnath *, Qiaohuan Cheng, Theresa G. Hedderman, Hugh J. Byrne,
} School of Physics, Focas Research Institute, Dublin Institute of Technology, Kevin Street, Dublin 8, Ireland.

\section{ABSTRACT}

The effectiveness of polycyclic aromatic hydrocarbons (PAHs) for selective solubilisation of single walled carbon nanotubes (SWCNTs) has been studied by Raman spectroscopy. Polyphenyl and polyacene PAHs of different lengths are used. Selective interaction between the PAHs and SWCNT is investigated by analyzing the Raman radial breathing modes the frequency positioning of which yields information concerning the diameter distribution of the SWCNT sample. Samples were dispersed at concentrations below the debundling limit and deposited on quartz substrates. A combination of four laser excitation energies was utilized to establish the distribution of diameters present. The results show that the PAHs interact with a range of SWCNT diameters. In general a preference for smaller diameter SWCNTs is evident, although the longer PAHs have the capacity to solubilise larger diameter SWCNTs, due to their increased binding energy. Although a small degree of structural specificity is evident, all PAHs solubilise both chiral and nonchiral SWCNTs.

*Corresponding author. Tel: +353 1 4027932. E-mail: $\underline{\text { Sourabhi.debnath@dit.ie }}$ (S.Debnath)

\section{Introduction}


Single walled carbon nanotubes (SWCNTs) are one of the most studied nanomaterials. SWCNTs are recognized as possessing high strength [1] and electrical [2] and thermal [3] conductivity promising a range of potential applications. However, the widespread use of SWCNTs is severely limited by the difficulties in processing due to the presence of bundles, levels of impurities and varying degrees of solubility in most solvents $[2,4,5]$. Furthermore, as prepared samples contain a broad range of SWCNTs of varying structures and electronic character, from metallic to semiconducting. It has been found that organic polymers such as poly PmPV-coDOctOPV and polycyclic aromatic hydrocarbons (PAHs) can solubilise and aid in the purification of the SWCNTs in organic solvents [6-10]. The interaction can cause the SWCNTs to disperse from their bundled form [6-10] and there is a strong suggestion that the organic species interact preferentially with SWCNTs of certain diameters or diameter range and even electronic structure $[6,7,11]$.

The PAHs anthracene and $p$-terphenyl (Fig.1) have previously been shown to aid in the effective solubilisation of SWCNTs [10], and, at low concentrations, have furthermore been shown to exfoliate the SWCNT bundles of the as-produced sample. The observed quenching of the fluorescence of the PAHs suggests a $\pi$ - $\pi$ stacking interaction $[10,11]$ and it may therefore be proposed that there is a preferential mapping of the structures based on the observation that the molecular structures of the acene oligomers match that of the backbone of armchair SWCNTs, while those of the phenyl series match that of the zig-zag SWCNTs [10-12]. The schematic representation of Fig. 2 is very simplistic as a staggered rather than commensurate mapping of PAHs on graphite is normally observed and is thus more probable [13]. Raman studies of SWCNTs solubilised and dispersed with the aid of anthracene and 
p-terphenyl have indicated that a selective solubilisation of semi-conducting SWCNTs by $p$-terphenyl and metallic by anthracene is indeed affected [11].

\section{Fig. 1- here}

Fig. 2- here

It is therefore of interest to systematically explore the interaction between PAHs and SWCNTs in order to optimize any selective solubilisation. Fluorescence quenching studies of the series of polyacenes from naphthalene to tetracene and the series of polyphenyls from biphenyl to $p$-quinquephenyl have illustrated that the binding energy systematically increases with increasing molecular weight $[8,9]$. It may be expected that the degree of selectivity may also show clear structural relationships and can thus be optimized. Thus, in this work, the selective solubilisation of SWCNTs by PAHs of varying structures (Fig. 1) is explored using Raman spectroscopy.

Raman spectroscopy is a powerful tool to investigate the vibrational properties and thus characterize SWCNTs. There are basically four phonon modes for SWCNTs that give significant and characteristic Raman scattering signals. The radial breathing modes (RBMs) are in the region of $\sim 200 \mathrm{~cm}^{-1}$ and the frequency positioning is related to the SWCNT diameter [14-16]. In this region carbon atoms undergo uniform radial displacement. The $\mathrm{D}$ band at $\sim 1350 \mathrm{~cm}^{-1}$ is reported to be related to either the presence of defects in the SWCNT walls or to the presence of amorphous carbon material in the sample [15]. The tangential carbon stretching modes (G- band) derive from the graphitic mode at $1582 \mathrm{~cm}^{-1}$ and their exact positioning can vary slightly depending for example on chemical environment [17], laser frequency [16] and temperature $[18,19]$. These modes are associated with the in phase 
vibrational movement of carbon atoms. The line-shape of G-band can be used to distinguish between metallic and semiconducting SWCNTs $[15,16,20]$. The $\mathrm{G}^{\prime}$ band is at $\sim 2704 \mathrm{~cm}^{-1}$. This feature is considered to be a second order overtone of the D band [20].

As the RBM frequency is related to the SWCNT diameter and the structural indices $(n, m)$, a Raman spectrum of a SWCNT sample can be employed to establish the range of diameters present in a sample [21]. It can thus also be employed to establish changes to that diameter range as a result of a structurally selective process. For each SWCNT of a different diameter with structural indices $(n, m)$, there is also a unique set of electronic energy levels in the conduction and valance bands, giving rise to resonances across the visible and near infra red spectrum which are characteristic of specific structures [22]. It was recognised at early stage, that for a given sample of SWCNTs containing a range of diameters, the Raman spectrum is dominated by the SWCNT which are resonant at the energy of the source laser [21]. Thus, for the complete characterisation of a sample of SWCNT, a broad range of laser excitation energies should be used [15].

To investigate the selective interaction of PAHs with SWCNTs, the diameters of the SWCNT composites were monitored via Raman RBMs. The RBM profile is a representation of the sample composition and can be used to determine its structural make-up. Isolated SWCNTs are identified by a single RBM line, and the frequency position can be used to identify the chiral indices and therefore electronic character of the SWCNTs Four different laser excitation energies were used to observe the range of SWCNT diameters within the composite sample. Composite samples were dispersed at concentrations below their dispersion limit $[8,9]$ to ensure that isolated SWCNTs were examined. The structures present in the composite samples are 
compared to the pristine sample of SWCNT, to ascertain the degree of selective interaction.

\section{Experimental}

As received High Pressure decomposition of Carbon monoxide (HiPco) SWCNTs (Carbon Nanotechnologies, Inc.) and PAHs (Sigma-Aldrich, Ireland), were used to prepare different composite solutions (1:1 mass ratio of SWCNT/PAH) with chloroform as solvent $[8,9]$. Chloroform was used because of its poor affinity for SWCNTs [23].

At the highest concentration, the composite solutions were sonicated using a sonic tip (Ultrasonic processor VCX $750 \mathrm{~W}$ ) for $3 \times 10 \mathrm{~s}$ at $38 \%$ of the power output. The samples were serially diluted by a factor of two down to the lowest concentration. After each dilution each sample was sonicated as described above and allowed to settle for $72 \mathrm{~h}$, after which the supernatant liquid from the composite samples was carefully withdrawn and allowed to settle for a further $24 \mathrm{~h}$.

From previous fluorescence studies [8,9] the regions where SWCNTs are dispersed to a maximum in the presence of PAHs of different lengths were obtained. At these concentrations the SWCNT bundles are fully dispersed. The concentration range was chosen such that it spanned the region of dispersion observed in these fluorescence based studies.

It was noted that for suspensions above the dispersion limit [8, 24], a considerable amount of precipitation of SWCNTs was observed and so the solubilisation is only partial. At concentrations where the SWCNTs are well dispersed, no precipitate was found. As composite solutions were prepared by using 
SWCNTs/PAHs in 1:1 (w/w), it can be stated that below the dispersion limit the concentration of PAHs and SWCNTs are the same.

The as prepared concentration range of SWCNTs, respect to the PAHs concentration, together with the dispersion concentration, are shown in Table 1.

Table 1 here

The sample below the dispersion limit for each PAH composite was chosen for the Raman characterization. For naphthalene, the concentrations of $\sim 3.12 \times 10^{-4} \mathrm{~mol} / \mathrm{L}$ and $\sim 1.46 \times 10^{-5} \mathrm{~mol} / \mathrm{L}$, tetracene of $\sim 4.76 \times 10^{-9} \mathrm{~mol} / \mathrm{L}$, biphenyl of $\sim 3.05 \times 10^{-7}$ $\mathrm{mol} / \mathrm{L}$ and $p$-quaterphenyl of $\sim 3.72 \times 10^{-11} \mathrm{~mol} / \mathrm{L}$ were drop cast onto a clean quartz substrates.

The Raman instrument used in this study was a LabRAM HR 800 Raman Microscope (Horiba Jobin Yvon) with a confocal imaging microscope system. Four laser lines, $785 \mathrm{~nm}(\sim 1.58 \mathrm{eV}) 240 \mathrm{~mW}, 660 \mathrm{~nm}(\sim 1.88 \mathrm{eV})$ at $80 \mathrm{~mW}, 532 \mathrm{~nm}(\sim$ $2.33 \mathrm{eV})$ at $40 \mathrm{~mW}$ and $473 \mathrm{~nm}(\sim 2.62 \mathrm{eV})$ at $40 \mathrm{~mW}$ were employed as sources. To study the effect of PAHs length on solubility and selectivity of SWCNTs, the four laser lines were used to extensively probe the range of diameters present in the composite samples. The resonant nature of the Raman scattering implies that SWCNTs of certain diameters are enhanced and only by employing a variety of source wavelengths a comprehensive picture of the diameter range of the SWCNT sample can be generated. The RBMs positioning enables the determination of the diameter and thus the chiral indices $(n, m)$ of the SWCNTs. Additionally, obtaining a map of each composite sample gives an indication of the degree of selective solubilisation by the PAHs in each composite. Spectra were acquired by mapping the field of view of the $25 \mu \mathrm{m} \times 25 \mu \mathrm{m}$. In this way on average fifty spectra for each 
sample were obtained. The RBM features obtained were fitted with a combination Lorentzian/Gaussian line shape using the instrument LabSpec software version 4.02.

\section{Results}

Fig. 3(a) shows the Raman RBM spectra of a pristine SWCNTs sample for the four different excitation laser lines. Due to the different resonance conditions [25], each different source wavelength gives rise to a markedly different profile. The diameter of SWCNT $(d)$ can be related to the RBM frequency $\omega_{R B M}$ and structural indices $(n, m)$ by the following equation [26]

$$
\omega_{R B M}=\frac{C_{1}}{d}+C_{2}=\frac{\pi C_{1}}{a_{c-c} \sqrt{3\left(n^{2}+n m+m^{2}\right)}}+C_{2}
$$

where,

$a_{c-c}$ is the distance between the C-C bonds, $0.144 \mathrm{~nm},[26]$

$C_{l}$ is a constant of proportionality [27],

$C_{2}$ is essentially a damping factor which accounts for a frequency shift dependent on the damping caused by the local environment of the SWCNT [25].

Fig. 3(b) combines the four different spectra of Fig. 3(a) by a simple addition of the respective spectra which have been normalized according to different acquisition time and laser power.

\section{Fig. 3- (a) and (b) here}

There is uncertainty in the selection of values for $C_{1}$ and $C_{2}$ from literatures. For the evaluation of SWCNT diameters (in the diameter range $0.7<\mathrm{d}<1.5 \mathrm{~nm}$ ) Rao et al. have used values of $C_{1}=224 \mathrm{~cm}^{-1} \mathrm{~nm}, C_{2}=14 \mathrm{~cm}^{-1}$ [28]. Yu et al. have used $C_{l}=$ 
$223.75 \mathrm{~cm}^{-1} \mathrm{~nm}, C_{2}=15 \mathrm{~cm}^{-1}$ [16], for semiconducting SWCNTs. Michael et al. and Bachilo et al. find $C_{1}=223.5 \mathrm{~cm}^{-1} \mathrm{~nm}, C_{2}=12.5 \mathrm{~cm}^{-1}[14,26]$ whereas Telg et al. find values of $C_{1}=220.4 \mathrm{~cm}^{-1} \mathrm{~nm}, C_{2}=19 \mathrm{~cm}^{-1}$ [29]. Fantain et al have tabulated two sets of $C_{1}$ and $C_{2}$ values: for semiconducting $C_{1}=223 \mathrm{~cm}^{-1} \mathrm{~nm}, C_{2}=10 \mathrm{~cm}^{-1}$ and metallic $C_{l}=220 \mathrm{~cm}^{-1} \mathrm{~nm}, C_{2}=14 \mathrm{~cm}^{-1}$ SWCNTs [30]. In other literature reports, the values of $C_{1}$ and $C_{2}$ are found to be $C_{1}=219 \pm 3 \mathrm{~cm}^{-1} \mathrm{~nm}, C_{2}=15 \pm 3 \mathrm{~cm}^{-1}$ [15]. Jorio et al have used $C_{1}=248 \mathrm{~cm}^{-1} \mathrm{~nm}$ considering $C_{2}=0 \mathrm{~cm}^{-1}$ for isolated SWCNTs [31]. Therefore, although it is well documented that the RBM frequency is related to the SWCNT diameter, the values of the parameters $\left(C_{1}\right.$ and $\left.C_{2}\right)$ to elucidate this are still under debate.

For this work the values for the parameters were obtained by a recently reported fitting method [32]. As the literature values of these parameters range from $216 \mathrm{~cm}^{-1}$ $\mathrm{nm}$ to $248 \mathrm{~cm}^{-1} \mathrm{~nm}$ and 10 to $19 \mathrm{~cm}^{-1}$ for $C_{1}$ and $C_{2}$ respectively, in this work two sets of $C_{1}\left(216 \mathrm{~cm}^{-1} \mathrm{~nm}\right.$ and $\left.234 \mathrm{~cm}^{-1} \mathrm{~nm}\right)$ and $C_{2}(17 \mathrm{~nm}$ and $10 \mathrm{~nm})$ values were used to initially obtain a potential diameter range for pristine SWCNTs. Having established the range of potential diameters of the SWCNT present from the RBM frequencies and equation 1 , an estimate of the most probable diameters contributing to the Raman spectrum at each source wavelength can be made, assuming that resonant SWCNTs dominate the Raman spectrum, by reference to the so-called Kataura plot [33] which graphically relates the optical transition energies of metallic and semiconducting SWCNTs with their diameters. After establishing the possible diameter range for specific laser energies, these diameters were then compared with the Kataura plot to find out whether SWCNTs of these diameters are resonant at the corresponding laser energy. For SWCNTs of diameter in the range of $\sim 0.7 \mathrm{~nm}$ to $\sim 1.4 \mathrm{~nm}$ (which is the 
typical diameter range for HiPco SWCNTs [34]), only semiconducting SWCNTs should be resonant at a laser energy of $\sim 1.58 \mathrm{eV}(785 \mathrm{~nm})$. Therefore, for this laser energy only the diameters of semiconducting SWCNTs in the selected diameter range were chosen. However, in many cases there exists more than one candidate corresponding to the particular $\omega_{R B M}$. To assign a single diameter to a corresponding $\omega_{R B M}$, the inverse of these chosen diameters were plotted against the corresponding value of $\omega_{R B M}$, as shown in Fig. 4. As there is a linear dependence between $\omega_{R B M}$ and the inverse diameter $(1 / d)[15]$, the plot should be a straight line. For a particular $\omega_{R B M}$, a particular diameter was selected from the best fit to the straight line. Also from this best fit, the value of $C_{1}$ and $C_{2}$ were found to be $221.5 \mathrm{~cm}^{-1} \mathrm{~nm}$ and $14.4 \mathrm{~cm}^{-1}$ respectively for $785 \mathrm{~nm}(1.58 \mathrm{eV})$. By using equation 1 , the structural indices $(n, m)$ of pristine SWCNTs for the corresponding diameters were obtained. Similarly, the diameters and the value of $C_{1}$ and $C_{2}$ for the different laser energies were found. The values of $C_{1}$ and $C_{2}$ thus obtained were $207.5 \mathrm{~cm}^{-1} \mathrm{~nm}$ and $29.1 \mathrm{~nm}$ for $660 \mathrm{~nm}(1.88$ $\mathrm{eV}), 233.0 \mathrm{~cm}^{-1} \mathrm{~nm}$ and $8.5 \mathrm{~nm}$ for $532 \mathrm{~nm}(2.33 \mathrm{eV})$ and $213.7 \mathrm{~cm}^{-1} \mathrm{~nm}$ and $22.7 \mathrm{~nm}$ for $473 \mathrm{~nm}(2.62 \mathrm{eV})$ laser frequency respectively. The diameters and corresponding assignments of SWCNTs within the pristine sample for the different laser energies are listed in Table. 2. It is noted that all diameters are in the range of $\sim 1.3 \mathrm{~nm}$ to $\sim 0.67 \mathrm{~nm}$ which correlates well with the nominal diameter range of HiPco samples [28].

Fig. 4- here

Table. 2 here 
It should be noted that within the range of SWCNTs identified, there are only two armchair, $(10,10),(7,7)$ and four zigzag SWCNTs $(11,0),(12,0),(16,0)$ and $(17,0)$, all others being chiral. A simple postulation that polyacene PAHs preferentially solubilise the armchair SWCNTs and polyphenyl PAHs the zigzag [10,11] may therefore be somewhat naïve.

Fig. 5 and 6 show examples of single point Raman spectra of pristine HiPco SWCNTs and SWCNT/naphthalene composite samples at two different concentrations respectively, using $532 \mathrm{~nm}$ as source. As observed in previous studies [8, 9], a comparison of Fig. 6 (a) and (b) demonstrates that the SWCNTs/naphthalene composite samples, at $\sim 1.17 \times 10^{-4} \mathrm{~mol} / \mathrm{L}$ SWCNTs are largely debundled and at lower concentrations, $\sim 1.46 \times 10^{-5} \mathrm{~mol} / \mathrm{L}$ one can expect predominantly isolated SWCNTs. The inset of theses figures show the RBM region of the corresponding sample and are corrected for the quartz substrate background. The RBMs region was then fitted using the LabSpec 4.02 instrument software.

\section{Fig. 5- here}

Fig. 6- (a) and (b) here

\section{Fig. 7- here}

A map of the SWCNT/naphthalene sample of concentration $\sim 1.46 \times 10^{-5}$ $\mathrm{mol} / \mathrm{L}$ was performed and although in all cases the RBM spectrum was predominantly singly featured, the spectral positioning varied significantly from point to point. A histogram of occurrence of single RBM features at specific frequencies was constructed for each source wavelength. Fig. 7 shows the histogram of such 
occurrences for the SWCNTs/naphthalene composite sample at concentration $1.46 \mathrm{x}$ $10^{-5} \mathrm{~mol} / \mathrm{L}$. In this plot the histograms represent the number of occurrences of SWCNTs of different diameters at the four different laser excitation energies.

The SWCNTs found in the composite sample should be present in the pristine sample. From Table 2 and Table 3, it can be seen that the $\omega_{R B M}$ positioning of the SWCNTs within the SWCNTs/naphthalene composite samples are up shifted by a few wave-numbers compared to those of pristine SWCNTs. This shift may be because of a change in bundle size of SWCNTs and/or a change in the local environment due to the presence of the PAH molecules [25]. However, irrespective of the shift of $\omega_{R B M}$ for the SWCNTs/naphthalene composites, the structural assignments made are consistent with those of the pristine SWCNTs samples, underlining the value of the fitting procedure [32].

\section{Table 3 here}

From Fig. 7 and Table 3 it is found that in comparison to the pristine SWCNTs, the SWCNTs/naphthalene composite is depleted in larger diameter SWCNTs yet rich in medium and smaller diameter SWCNT ( $\sim 1 \mathrm{~nm}$ to $\sim 0.7 \mathrm{~nm})$ indicating a degree of structurally selectivity. Notably, however, the armchair SWCNT $(10,10)$ is missing from the list although there is a strong contribution from the $(7,7)$ armchair SWCNT. The zigzag SWCNTs $(11,0)$ and $(12,0)$ also feature, although not prominently.

Fig. 8- here 
Similar to Fig. 7, the histogram representing the number of occurrences of SWCNTs of different diameters for the SWCNT/biphenyl composite sample at concentration $\sim 3.05 \times 10^{-7} \mathrm{~mol} / \mathrm{L}$ at four different laser excitation energies is shown in Fig. 8.

Shifts in $\omega_{R B M}$ position of SWCNTs of SWCNTs/biphenyl composite sample are again observed. However, structural assignments correlate with Table 4 and Table 2. Comparing the profile of the SWCNTs/naphthalene composite (Fig. 7 and Table 3) and SWCNT/biphenyl composite (Fig. 8 and Table 4), it can be seen that the biphenyl composite sample is relatively rich in SWCNTs of larger diameters, although it is still depleted in SWCNT of diameters > $1.09 \mathrm{~nm}$ compared to the pristine sample.

\section{Table 4 here}

The increased efficiency of the biphenyl in binding to the larger diameter SWCNT can be explained in terms of the increased binding energy per molecule as determined from fluorescence quenching measurements $[8,9]$. In terms of structural selectivity, the zigzag $(11,0)$ SWCNT features in the histogram, although not prominently.

\section{Fig. 9- here}

\section{Table 5 here}

The histograms representing the number of occurrences of different diameters SWCNTs of SWCNT/tetracene composite sample at concentration $\sim 4.76 \times 10^{-9}$ $\mathrm{mol} / \mathrm{L}$ at four different laser excitation energies is shown in Fig. 9. Table 5 shows the RBM frequencies and corresponding structure assignments for SWCNT of the SWCNTs/tetracene composite sample at different laser excitation energies. 
As with the naphthalene and biphenyl composite samples, shifts with respect to the pristine SWCNT are also observed for the SWCNTs/tetracene composites. Assignments once again are consistent with those observed in the pristine samples.

From Table 3 and Table 5 it is found that the diameter range of SWCNTs selected by naphthalene is also selected by tetracene. But each PAH has a preference for specific diameters within the range (Fig. 7 and Fig. 9). Comparing the profile of solubilised SWCNTss of SWCNTs/tetracene (Fig. 9 and Table 5) to those of the SWCNTs/naphthalene (Fig. 7 and Table 3) and SWCNTs/biphenyl (Fig. 8 and Table 4), it can be found that tetracene selects a greater amount of the larger diameters SWCNT compared to naphthalene. This may be explained by the fact that tetracene has a higher binding energy than naphthalene [8,9]. Comparing Fig. 8 and 9, the diameter range of SWCNTs selected are similar although it appears that tetracene exhibits a higher propensity for the larger diameter SWCNT. Again this may be explained by the larger binding energy of tetracene. As in the case of the naphthalene composite, the $(7,7)$ armchair SWCNT features prominently.

\section{Fig. 10- here}

\section{Table 6 here}

The histograms representing the number of occurrences of different diameters SWCNTs of SWCNTs/p-quaterphenyl composite sample at concentration $\sim 3.72 \times 10$

${ }^{11} \mathrm{~mol} / \mathrm{L}$ at four different laser excitation energies is shown in Fig. 10. From Table 6, the RBM frequencies and corresponding structural assignments for SWCNT of 
$\mathrm{SWCNT} / p$-quaterphenyl at different laser energies can be found. Again, shifts in $\omega_{R B M}$ values compared to that of pristine SWCNTs, are observed.

For the case of SWCNT/p-quaterphenyl it is reasonable to expect that as the binding energy of $p$-quaterphenyl is higher than that of other three PAHs, $p$ quaterphenyl will show better selectivity for SWCNTs of larger diameters. But in reality this is not observed to be the case. Solubilisation in SWCNT/p-quaterphenyl composites seems to favour SWCNTs of medium and some smaller diameters. This may be because the structure of $p$-quaterphenyl (similar to biphenyl) is not rigid and therefore torsion between phenyl rings is also very high resulting in poor solubilisation of SWCNTs of larger diameters. In terms of structural selectivity, in the case of the $p$-quaterphenyl composite, the $(11,0)$ zigzag SWCNT features strongly.

\section{Discussion}

It has previously been speculated that structurally selective solubility can be affected by interaction with PAHs, on the basis that the polyacene series are structurally similar to the longitudinal surface of the metallic armchair SWCNTs and the polyphenyl series to that of predominantly semiconducting zigzag SWCNTs [10]. A preferential solubilisation of semiconducting SWCNTs by $p$-terphenyl and of metallic by anthracene has previously reported for laser vaporised SWCNTs [11]. In this study of HiPco SWCNTs, it is firstly clear that the as produced samples are dominated by chiral SWCNTs and relatively few nonchiral SWCNTs are present. Below the dispersion limit, each PAH solubilises a range of both chiral and nonchiral SWCNTs. The shorter chain PAHs more efficiently solubilise and disperse the SWCNTs, as evidenced by the dispersion limits of $4 \times 10^{-2} \mathrm{mg} / \mathrm{ml}$ for naphthalene, 
$2.4 \times 10^{-3} \mathrm{mg} / \mathrm{ml}$ for biphenyl although there appears to be a preference for the smaller diameter SWCNTs. The longer PAHs are less efficient at solubilising and dispersing the SWCNTs $\left(3.48 \times 10^{-5} \mathrm{mg} / \mathrm{ml}\right.$ for tetracene, $1.82 \times 10^{-7} \mathrm{mg} / \mathrm{ml}$ for $p$-quaterphenyl) although the solubilisation of the larger diameter SWCNTs is more efficient. The greater affinity of the longer PAHs for the larger diameter SWCNTs can be understood in terms of their greater binding energies $[8,9]$. In terms of structural selectivity, it is notable that only the polyacene moieties solubilise the armchair SWCNTs, although biphenyl also solubilises the $(11,0)$ and $(12,0)$ zig-zag SWCNTs. The polyphenyl moieties do not solubilise the armchair SWCNTs. However, in none of the four composite samples is the solubilisation of nonchiral SWCNTs dominant, indicating that a simple mapping of the PAH structure onto the SWCNT longitudinal surface is somewhat naïve.

Given the systematic structural dependence of the binding energy of PAHs to mixed SWCNT samples, it is reasonable to expect that the binding interaction should be optimal for a direct mapping of the PAH structure onto the linear backbone of matched SWCNT structures. However, the results here suggest a binding which is not specific to structure or chirality. It must therefore be postulated that the smaller PAHs can relatively efficiently bind normal to the tube axis of nonchiral nanotubes and along the direction of the chiral vector of chiral nanotubes. Given the curvature of the SWCNTs, this is more efficient for the smaller PAHs on small diameter SWCNTs, the longer PAHs interacting more efficiently with larger diameter SWCNTs. Additionally, the polyphenyl PAHs have a degree of rotational freedom about the inter-phenyl bond which may inhibit structurally specific binding. PAHs are also known to stack orthogonal to the surface of graphite, although this is energetically 
favourable only at high coverage [13]. A correlation of such steric and energetic considerations may reduce any structural selectivity.

\section{Conclusion}

A detailed Raman study of the diameter profiles of SWCNTs solubilised by a range of PAHs demonstrates that they are capable of selecting from the range of SWCNTs present in the as received sample. In general a preference for smaller diameter SWCNTs is evident, although the longer PAHs have the capacity to solubilise larger diameter SWCNTs, due to their increased binding energy. Although a small degree of structural specificity is evident, all PAHs solubilise both chiral and nonchiral SWCNTs.

\section{Acknowledgement}

This project is funded under the Science Foundation Ireland Research Frontiers Program PHY037 2006. The Raman Instrument was purchased under the framework of the INSPIRE programme, funded by the Irish Government's Programme for Research in Third Level Institutions, Cycle 4, National Development Plan 2007-2013, supported by the European Union Structural Fund. 


\section{References}

[1] Yu MF, Files BS, Arepalli S, Ruoff RS. Tensile loading of ropes of single wall carbon nanotubes and their mechanical properties. Physical Review Letters, 2000; 84(24): 5552-5555.

[2] Thess A, Lee R, Nikolaev P, Dai HJ, Petit P, Robert J, et al. Crystalline ropes of metallic carbon nanotubes. Science, 1996; 273(5274): 483-487.

[3] Hone J, Whitney M, Piskoti C, Zettl A. Thermal conductivity of single-walled carbon nanotubes. Physical Review B, 1999; 59(4): R2514-R2516.

[4] Baughman RH, Zakhidov AA, de Heer WA. Carbon nanotubes - the route toward applications. Science, 2002. 297(5582); 787-792.

[5] Journet C, Maser WK, Bernier P, Loiseau A, delaChapelle ML, Lefrant S, et al. Large-scale production of single-walled carbon nanotubes by the electricarc technique. Nature, 1997; 388(6644): 756-758.

[6] Dalton AB, Blau WJ, Chambers G, Coleman JN, Henderson K, Lefrant S, et al. A functional conjugated polymer to process, purify and selectively interact with single wall carbon nanotubes. Synthetic Metals, 2001; 121(1-3): 12171218.

[7] Dalton AB, Stephan C, Coleman JN, McCarthy B, Ajayan PM, Lefrant S, et al. Selective interaction of a semiconjugated organic polymer with single-wall nanotubes. Journal of Physical Chemistry B, 2000; 104(43): 10012-10016. 
[8] Debnath S, Cheng QH, Hedderman TG, Byrne HJ. A study of the interaction between single-walled carbon nanotubes and polycyclic aromatic hydrocarbons: Toward structure-property relationships. Journal of Physical Chemistry C, 2008; 112(28): 10418-10422.

[9] Debnath S, Cheng QH, Hedderman TG, Byrne HJ. An experimental study of the interaction between single walled carbon nanotubes and polycyclic aromatic hydrocarbons. Physica Status Solidi B-Basic Solid State Physics, 2008; 245(10): 1961-1963.

[10] Hedderman TG, Keogh SM, Chambers G, Byrne HJ. Solubilization of SWNTs with organic dye molecules. Journal of Physical Chemistry B, 2004; 108(49): 18860-18865.

[11] Hedderman TG, Keogh SM, Chambers G, Byrne HJ. In-depth study into the interaction of single walled carbon nanotubes with anthracene and p-terphenyl. Journal of Physical Chemistry B, 2006; 110(9): 3895-3901.

[12] Gregan E, Keogh SM, Maguire A, Hedderman TG, Neill LO, Chambers G, et al. Purification and isolation of SWNTs. Carbon, 2004; 42(5-6): 1031-1035.

[13] Zacharia R, Ulbricht $\mathrm{H}$, Hertel $\mathrm{T}$. Interlayer cohesive energy of graphite from thermal desorption of polyaromatic hydrocarbons. Physical Review B, 2004; 69(15): 155406-1-155406-7.

[14] Bachilo SM, Strano MS, Kittrell C, Hauge RH, Smalley RE, Weisman RB. Structure-assigned optical spectra of single-walled carbon nanotubes. Science, 2002; 298(5602): 2361-2366.

[15] Dresselhaus MS, Dresselhaus G, Jorio A. Raman spectroscopy of carbon nanotubes in 1997 and 2007. Journal of Physical Chemistry C, 2007; 111(48): 17887-17893. 
[16] Yu ZH, Brus L. Rayleigh and Raman scattering from individual carbon nanotube bundles. Journal of Physical Chemistry B, 2001; 105(6): 1123-1134.

[17] Lafi L, Cossement D, Chahine R. Raman spectroscopy and nitrogen vapour adsorption for the study of structural changes during purification of singlewall carbon nanotubes. Carbon, 2005; 43(7): 1347-1357.

[18] Chiashi S, Murakami Y, Miyauchi Y, Maruyama S. Temperature measurements of single-walled carbon nanotubes by Raman scattering. Thermal Science \& Engineering, 1999.7 (4): 10-11.

[19] Karachevtseva VA, Glamazda AY, Dettlaff-Weglikowska U, Kurnosov VS, Obraztsova ED, Peschanskii AV, Eremenko VV, Roth S. Raman spectroscopy of HiPCO single-walled carbon nanotubes at 300 and 5 K. Carbon, 2003; 41(8): $1567-1574$.

[20] Dresselhaus MS, Dresselhaus G, Jorio A, Souza AG, Saito R. Raman spectroscopy on isolated single wall carbon nanotubes. Carbon, 2002; 40(12): 2043-2061.

[21] Rao AM, Richter E, Bandow S, Chase B, Eklund PC, Williams KA, et al. Diameter-selective Raman scattering from vibrational modes in carbon nanotubes. Science, 1997; 275(5297): 187-191.

[22] Nair N, Usrey ML, Kim WJ, Braatz RD, Strano MS. Estimation of the (n,m) concentration distribution of single-walled carbon nanotubes from photoabsorption spectra. Analytical Chemistry, 2006; 78(22): 7689-7696.

[23 Cheng QH, Debnath S, Gregan E, Byrne HJ. Effect of Solvent Solubility Parameters on the Dispersion of Single-Walled Carbon Nanotubes. Journal of Physical Chemistry C, 2008; 112(51): 20154-20158. 
[24] Giordani S, Bergin SD, Nicolosi V, Lebedkin S, Kappes MM, Blau WJ, et al. Debundling of single-walled nanotubes by dilution: Observation of large populations of individual nanotubes in amide solvent dispersions. Journal of Physical Chemistry B, 2006; 110(32): 15708-15718.

[25] Kuzmany H, Plank W, Hulman M, Kramberger C, Gruneis A, Pichler T, et al. Determination of SWCNT diameters from the Raman response of the radial breathing mode. European Physical Journal B, 2001; 22(3): 307-320.

[26] Strano MS, Doorn SK, Haroz EH, Kittrell C, Hauge RH, Smalley RE. Assignment of (n, m) Raman and optical features of metallic single-walled carbon nanotubes. Nano Letters, 2003; 3(8): 1091-1096.

[27] Hahm MG, Kwon YK, Lee E, Ahn CW, Jung YJ. Diameter Selective Growth of Vertically Aligned Single Walled Carbon Nanotubes and Study on Their Growth Mechanism. Journal of Physical Chemistry C, 2008; 112(44): 1714317147.

[28] Rao AM, Chen J, Richter E, Schlecht U, Eklund PC, Haddon RC, et al. Effect of van der Waals interactions on the Raman modes in single walled carbon nanotubes. Physical Review Letters, 2001; 86(17): 3895-3898.

[29] Telg H, Maultzsch J, Reich S, Hennrich F, Thomsen C. Chirality distribution and transition energies of carbon nanotubes Physical Review Letters, 2004; 93(18): 177401(1)-177401(4).

[30] Fantini C, Jorio A, Souza M, Strano MS, Dresselhaus MS, Pimenta MA. Optical transition energies for carbon nanotubes from resonant Raman spectroscopy: Environment and temperature effects. Physical Review Letters, 2004; 93(14): 147406(1)-147406(4). 
[31] Jorio A, Saito R, Hafner JH, Lieber CM, Hunter M, McClure T, et al. Structural $(n, m)$ determination of isolated single-wall carbon nanotubes by resonant Raman scattering. Physical Review Letters, 2001; 86(6): 1118-1121.

[32] Cheng QH, Debnath S, Gregan E, Byrne HJ. Vibrational mode assignments for bundled single-wall carbon nanotubes using Raman spectroscopy at different excitation energies. Carbon, 2009. Submitted.

[33] Kataura H, Kumazawa Y, Maniwa Y, Umezu I, Suzuki S, Ohtsuka Y, et al. Optical properties of single-wall carbon nanotubes. Synthetic Metals, 1999; 103(1-3): 2555-2558.

[34] Nikolaev P, Bronikowski MJ, Bradley RK, Rohmund F, Colbert DT, Smith KA, et al. Gas-phase catalytic growth of single-walled carbon nanotubes from carbon monoxide. Chemical Physics Letters, 1999; 313(1-2): 91-97.

Tables

Table 1- Concentration range of each PAH composite

\begin{tabular}{ccc}
\hline PAH & Concentration range $(\mathrm{mol} / \mathrm{L})$ & $\begin{array}{c}\text { Dispersion concentration } \\
(\mathrm{mol} / \mathrm{L})\end{array}$ \\
\hline Naphthalene & $\sim 2.50 \times 10^{-3}$ to $\sim 1.22 \times 10^{-6}$ & $\sim 3.12 \times 10^{-4}$ \\
Tetracene & $\sim 3.125 \times 10^{-4}$ to $\sim 1.8626 \times 10^{-11}$ & $\sim 1.52 \times 10^{-7}$ \\
Biphenyl & $\sim 5 \times 10^{-3}$ to $\sim 2.38 \times 10^{-9}$ & $\sim 1.56 \times 10^{-4}$ \\
$p$-Quaterphenyl & $\sim 1.25 \times 10^{-3}$ to $\sim 3.637 \times 10^{-14}$ & $\sim 5.96 \times 10^{-10}$ \\
\hline
\end{tabular}

Table 2- RBMs shift and the corresponding structure assignments for pristine SWCNTs at different laser energy excitations. 


\begin{tabular}{|c|c|c|c|c|c|c|c|c|c|c|c|}
\hline \multicolumn{3}{|c|}{$\begin{array}{l}785 \mathrm{~nm} \\
1.58 \mathrm{eV}\end{array}$} & \multicolumn{3}{|c|}{$\begin{array}{l}660 \mathrm{~nm} \\
1.88 \mathrm{eV}\end{array}$} & \multicolumn{3}{|c|}{$\begin{array}{l}532 \mathrm{~nm} \\
2.33 \mathrm{eV}\end{array}$} & \multicolumn{3}{|c|}{$\begin{array}{l}473 \mathrm{~nm} \\
2.62 \mathrm{eV}\end{array}$} \\
\hline $\begin{array}{l}\omega_{R B M S} \\
\left(\mathbf{c m}-{ }^{-1}\right)\end{array}$ & $\begin{array}{l}d \\
(\mathbf{n m}) \\
\end{array}$ & $(n, m)$ & $\begin{array}{l}\omega_{R B M S} \\
(\mathbf{c m - 1})\end{array}$ & $\begin{array}{l}d \\
(\mathbf{n m}) \\
\end{array}$ & $(n, m)$ & $\begin{array}{l}\omega_{\mathrm{RBMs}} \\
\left(\mathbf{c m}^{-1}\right) \\
\end{array}$ & $\begin{array}{l}d \\
(\mathrm{~nm}) \\
\end{array}$ & $(n, m)$ & $\begin{array}{l}\omega_{R B M S} \\
(\mathbf{c m - 1}) \\
\end{array}$ & $\begin{array}{l}d \\
(\mathbf{n m}) \\
\end{array}$ & $(n, m)$ \\
\hline $\begin{array}{l}207.6 \\
217.7 \\
227.7 \\
236.5 \\
249.6 \\
261.4 \\
269.9 \\
307.1\end{array}$ & $\begin{array}{l}1.145 \\
1.102 \\
1.032 \\
0.994 \\
0.936 \\
0.894 \\
0.873 \\
0.757\end{array}$ & $\begin{array}{l}(12,4) \\
(9,7) \\
(8,7) \\
(12,1) \\
(10,3) \\
(7,6) \\
(11,0) \\
(6,5)\end{array}$ & $\begin{array}{l}180.2 \\
186.2 \\
193.6 \\
216.1 \\
224.0 \\
243.0 \\
250.0 \\
254.7 \\
262.4 \\
281.8 \\
294.9\end{array}$ & $\begin{array}{l}1.375 \\
1.326 \\
1.260 \\
1.111 \\
1.068 \\
0.965 \\
0.936 \\
0.915 \\
0.884 \\
0.828 \\
0.781\end{array}$ & $\begin{array}{l}(10,10) \\
(15,3) \\
(12,6) \\
(10,6) \\
(11,4) \\
(8,6) \\
(10,3) \\
(11,1) \\
(10,2) \\
(7,5) \\
(8,3)\end{array}$ & $\begin{array}{l}182.4 \\
192.5 \\
213.7 \\
222.5 \\
233.2 \\
244.8 \\
254.0 \\
268.3 \\
278.0 \\
295.9 \\
317.2\end{array}$ & $\begin{array}{l}1.349 \\
1.270 \\
1.125 \\
1.091 \\
1.038 \\
0.991 \\
0.952 \\
0.901 \\
0.858 \\
0.805 \\
0.777\end{array}$ & $\begin{array}{l}(13.6) \\
(16,0) \\
(11,5) \\
(12,3) \\
(9,6) \\
(10,4) \\
(12,0) \\
(8,5) \\
(9,3) \\
(9,2) \\
(6,5)\end{array}$ & $\begin{array}{l}180.9 \\
196.0 \\
204.8 \\
218.5 \\
229.3 \\
244.5 \\
258.4 \\
271.1 \\
288.2 \\
305.5 \\
330.5 \\
338.7\end{array}$ & $\begin{array}{l}1.335 \\
1.232 \\
1.169 \\
1.091 \\
1.038 \\
0.962 \\
0.901 \\
0.858 \\
0.805 \\
0.757 \\
0.692 \\
0.678\end{array}$ & $\begin{array}{l}(17,0) \\
(10,8) \\
(13,3) \\
(12,3) \\
(9,6) \\
(7,7) \\
(8,5) \\
(9,3) \\
(9,2) \\
(6,5) \\
(6,4) \\
(8,1)\end{array}$ \\
\hline
\end{tabular}

Table 3- RBM frequencies and the corresponding structural assignments for the SWCNT/naphthalene composite sample at different laser energies.

\begin{tabular}{|c|c|c|c|c|c|c|c|}
\hline \multicolumn{2}{|c|}{$\begin{array}{l}785 \mathrm{~nm} \\
1.58 \mathrm{eV}\end{array}$} & \multicolumn{2}{|c|}{$\begin{array}{l}660 \mathrm{~nm} \\
1.88 \mathrm{eV}\end{array}$} & \multicolumn{2}{|c|}{$\begin{array}{l}532 \mathrm{~nm} \\
2.33 \mathrm{eV}\end{array}$} & \multicolumn{2}{|c|}{$\begin{array}{l}473 \mathrm{~nm} \\
2.62 \mathrm{eV}\end{array}$} \\
\hline $\begin{array}{l}\omega_{R B M S} \\
(\mathbf{c m - 1})\end{array}$ & $(n, m)$ & $\begin{array}{l}\omega_{R B M S} \\
\left(\mathrm{~cm}^{-1}\right)\end{array}$ & $(n, m)$ & $\begin{array}{c}\omega_{R B M S} \\
\left(\mathbf{c m}^{1}\right)\end{array}$ & $(n, m)$ & $\begin{array}{l}\omega_{R B M S} \\
\left(\mathbf{c m}^{-1}\right)\end{array}$ & $(n, m)$ \\
\hline $\begin{array}{l}217.3 \\
229.2 \\
237.3 \\
270.4 \\
297.5\end{array}$ & $\begin{array}{l}(9,7) \\
(8,7) \\
(12,1) \\
(11,0) \\
(6,5)\end{array}$ & $\begin{array}{l}265 \\
283 \\
298.8\end{array}$ & $\begin{array}{l}(10,2) \\
(7,5) \\
(8,3)\end{array}$ & $\begin{array}{l}254.3 \\
283.5\end{array}$ & $\begin{array}{l}(12,0) \\
(9,3)\end{array}$ & $\begin{array}{l}245.6 \\
315\end{array}$ & $\begin{array}{l}(7,7) \\
(6,5)\end{array}$ \\
\hline
\end{tabular}

Table 4- RBM frequencies and the corresponding structure assignments for SWCNTs/biphenyl composite sample at different laser energies. 


\begin{tabular}{|c|c|c|c|c|c|c|c|}
\hline \multicolumn{2}{|c|}{$\begin{array}{c}785 \mathrm{~cm}^{1} \\
1.58 \mathrm{eV}\end{array}$} & \multicolumn{2}{|c|}{$\begin{array}{c}660 \mathrm{~cm}^{1} \\
1.88 \mathrm{eV}\end{array}$} & \multicolumn{2}{|c|}{$\begin{array}{c}532 \mathrm{~cm}^{1} \\
2.33 \mathrm{eV}\end{array}$} & \multicolumn{2}{|c|}{$\begin{array}{c}473 \mathrm{~cm}^{1} \\
2.62 \mathrm{eV}\end{array}$} \\
\hline $\begin{array}{l}\omega_{R B M s} \\
\left(\mathrm{~cm}^{1}\right)\end{array}$ & $(n, m)$ & $\begin{array}{c}\omega_{R B M s} \\
\left(\mathrm{~cm}^{1}{ }^{1}\right)\end{array}$ & $(n, m)$ & $\begin{array}{l}\omega_{R B M s} \\
\left(\mathrm{~cm}^{1}{ }^{1}\right.\end{array}$ & $(n, m)$ & $\begin{array}{l}\omega_{R B M s} \\
\left(\mathrm{~cm}^{1}{ }^{1}\right)\end{array}$ & $(n, m)$ \\
\hline $\begin{array}{l}228.4 \\
236.5 \\
268.2\end{array}$ & $\begin{array}{l}(8,7) \\
(12,1) \\
(11,0)\end{array}$ & $\begin{array}{l}284.2 \\
298.4\end{array}$ & $\begin{array}{l}(7,5) \\
(8,3)\end{array}$ & 274 & $(9,3)$ & $\begin{array}{l}207.7 \\
237 \\
287.8 \\
315\end{array}$ & $\begin{array}{l}(13,3) \\
(9,6) \\
(9,2) \\
(6,5)\end{array}$ \\
\hline
\end{tabular}

Table 5- RBMs shift and the corresponding structure assignments for SWCNTs/tetracene composite sample at different laser energies.

\begin{tabular}{|c|c|c|c|c|c|c|c|}
\hline \multicolumn{2}{|c|}{$\begin{array}{c}785 \mathrm{~cm}^{1} \\
1.58 \mathrm{eV}\end{array}$} & \multicolumn{2}{|c|}{$\begin{array}{c}660 \mathrm{~cm}^{1} \\
1.88 \mathrm{eV}\end{array}$} & \multicolumn{2}{|c|}{$\begin{array}{c}532 \mathrm{~cm}^{1} \\
2.33 \mathrm{eV}^{-}\end{array}$} & \multicolumn{2}{|c|}{$\begin{array}{l}473 \mathrm{~cm}^{1} \\
2.62 \mathrm{eV}\end{array}$} \\
\hline $\begin{array}{l}\omega_{R B M} \\
\left(\mathrm{~cm}^{-1}\right)\end{array}$ & $(n, m)$ & $\begin{array}{l}\omega_{R B M} \\
\left(\mathrm{~cm}^{-1}\right)\end{array}$ & $(n, m)$ & $\begin{array}{l}\omega_{R B M} \\
\left(\mathrm{~cm}^{-}\right.\end{array}$ & $(n, m)$ & $\begin{array}{l}\omega_{R B M} \\
\left(\mathrm{~cm}^{1}\right)\end{array}$ & $(n, m)$ \\
\hline $\begin{array}{l}220.7 \\
230.0 \\
237.5\end{array}$ & $\begin{array}{l}(9,7) \\
(8,7) \\
(12,1)\end{array}$ & $\begin{array}{l}263 \\
284 \\
298.8\end{array}$ & $\begin{array}{l}(10,2) \\
(7,5) \\
(8,3)\end{array}$ & $\begin{array}{l}243 \\
279\end{array}$ & $\begin{array}{l}(10,4) \\
(9,3)\end{array}$ & $\begin{array}{l}209.4 \\
244.9 \\
317.3\end{array}$ & $\begin{array}{l}(13,3) \\
(7,7) \\
(6,5)\end{array}$ \\
\hline
\end{tabular}

Table 6- RBM frequencies and the corresponding structure assignments for SWCNTs/p-quaterphenyl composite sample at different laser excitation energies.

\begin{tabular}{|c|c|c|c|c|}
\hline $\begin{array}{l}785 \mathrm{~nm} \\
1.58 \mathrm{eV}\end{array}$ & $\begin{array}{l}660 \mathrm{~nm} \\
1.88 \mathrm{eV}\end{array}$ & $\begin{array}{l}532 \mathrm{~nm} \\
2.33 \mathrm{eV}\end{array}$ & & $\begin{array}{l}\mathrm{nm} \\
\mathrm{eV}\end{array}$ \\
\hline $\begin{array}{ll}\omega_{R B M} & (n, m) \\
\left(\mathbf{c m}^{1}\right) & \end{array}$ & $\begin{array}{l}\omega_{R B M} \\
\left(\mathrm{~cm}^{1}\right)\end{array}$ & $\begin{array}{ll}\omega_{R B M} & (n, m) \\
\left(\mathrm{cm}^{1}\right) & \end{array}$ & $\begin{array}{l}\omega_{R B M} \\
\left(\mathbf{c m}^{1}\right)\end{array}$ & $(n, m)$ \\
\hline
\end{tabular}




\begin{tabular}{ll|ll|ll|ll}
\hline 229.1 & $(8,7)$ & 283 & $(7,5)$ & 280 & $(9,3)$ & 208.5 & $(13,3)$ \\
236.7 & $(12,1)$ & 299.6 & $(8,3)$ & & & 238.5 & $(9,6)$ \\
268.8 & $(11,0)$ & & & & & 291.7 & $(9,2)$ \\
& & & & & & 315.5 & $(6,5)$ \\
\hline
\end{tabular}

Figures

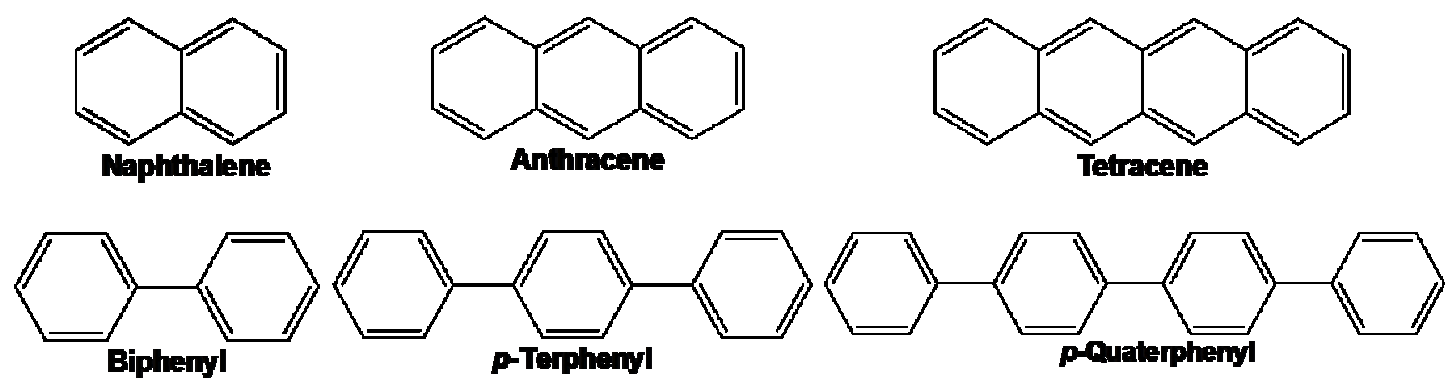

Fig. 1- PAHs of polyacene and polyphenyl series. 


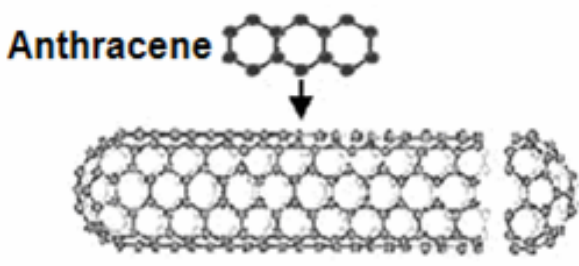

Single wall carbon nanotube (armchair)

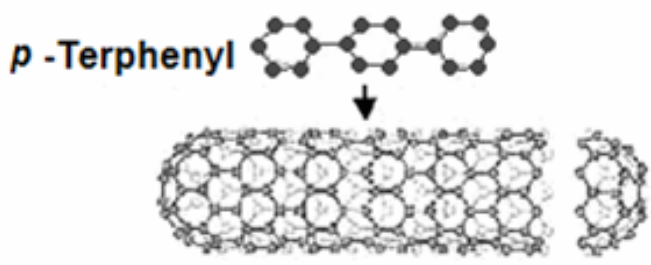

Single wall carbon nanotube (zig-zag)

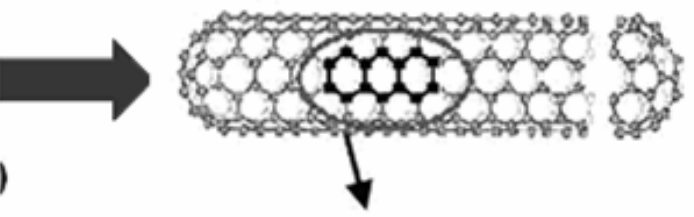

Individual molecules mapped onto respective nanotubes

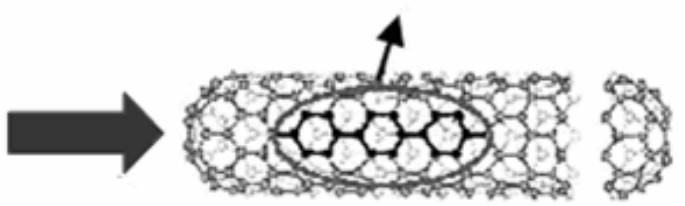

Fig. 2- Schematic representation of the mapping of anthracene to armchair SWCNT and $p$-terphenyl to zigzag SWCNT [12].

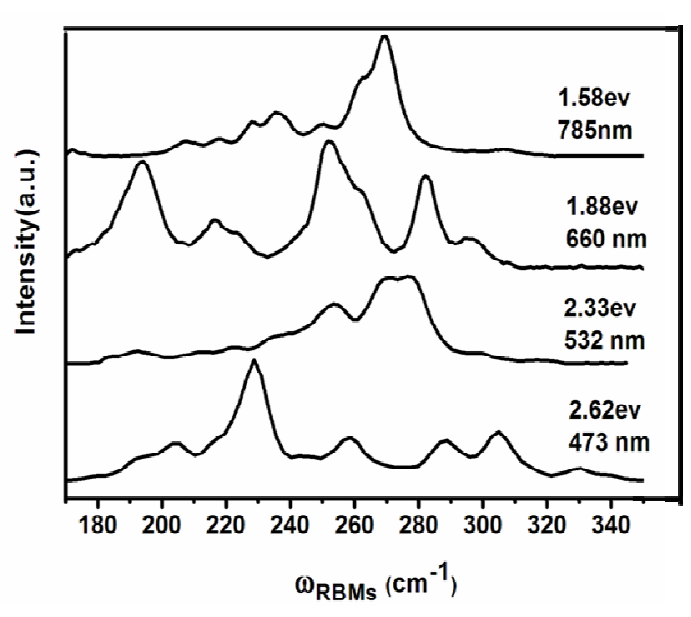

(a)

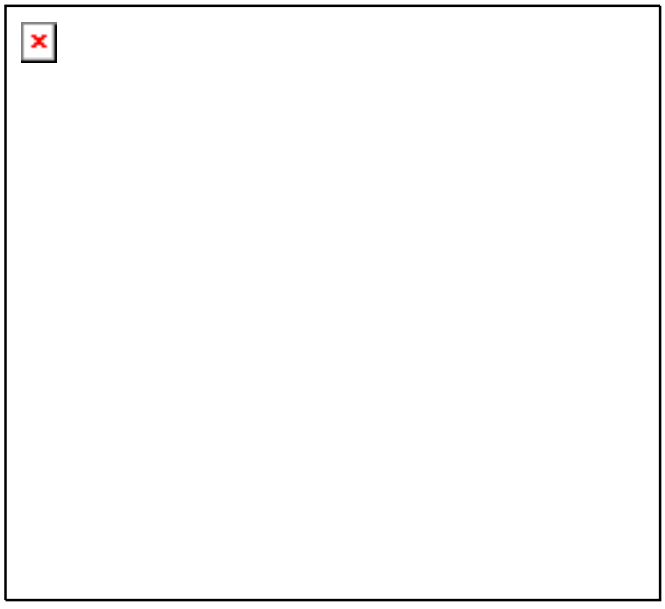

(b)

Fig 3- (a) RBMs of pristine SWCNT with $785 \mathrm{~nm}(1.58 \mathrm{eV}), 660 \mathrm{~nm}(1.88 \mathrm{eV})$, $532 \mathrm{~nm}(2.33 \mathrm{eV})$ and $473(2.62 \mathrm{eV})$ as source.

(b) Combined Raman spectra for the different lasers. 


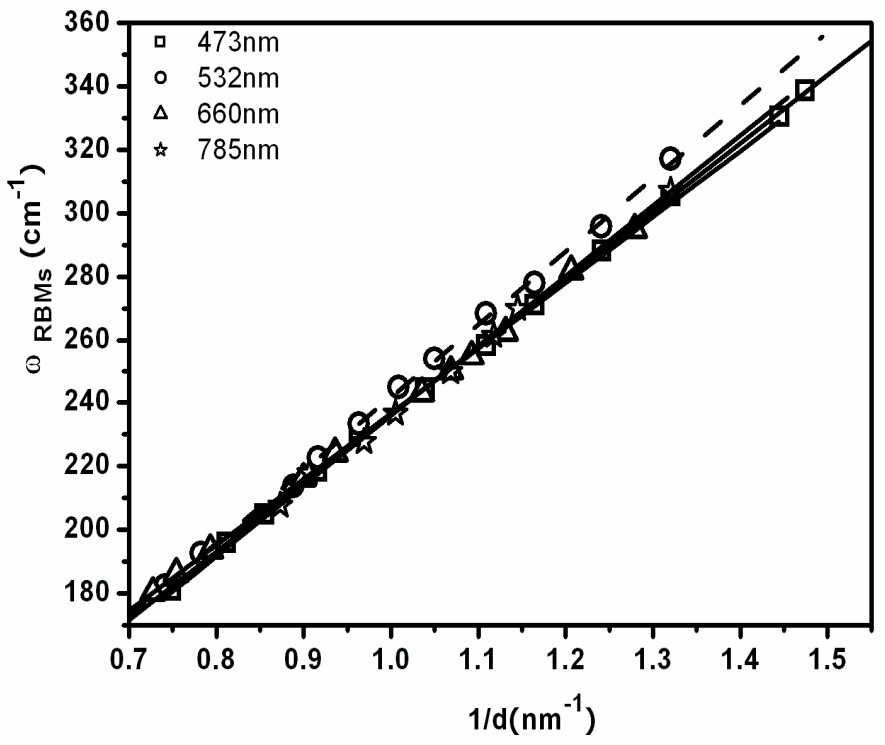

Fig. 4- A plot of $\omega_{R B M}$ versus inverse of pristine SWCNTs diameters (1/d)

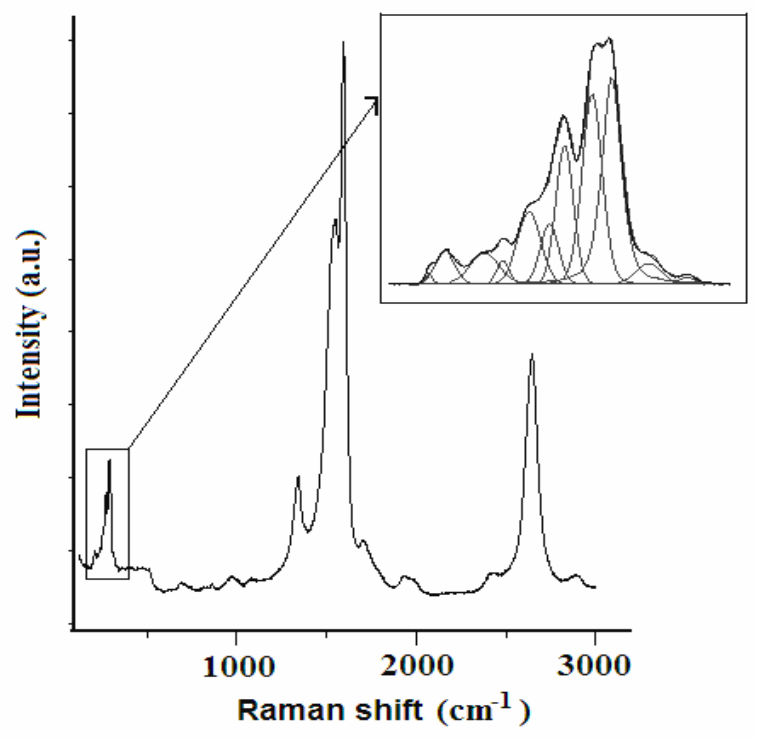

Fig. 5- Raman spectrum of pristine HiPco SWCNTs at 532nm $(2.33 \mathrm{eV})$ laser. Inset is the RBMs of HiPco SWCNTs. 


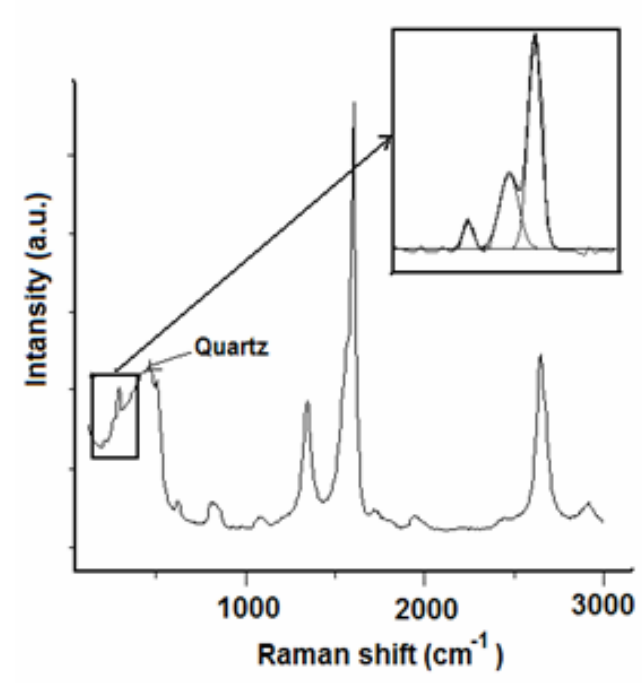

(a)

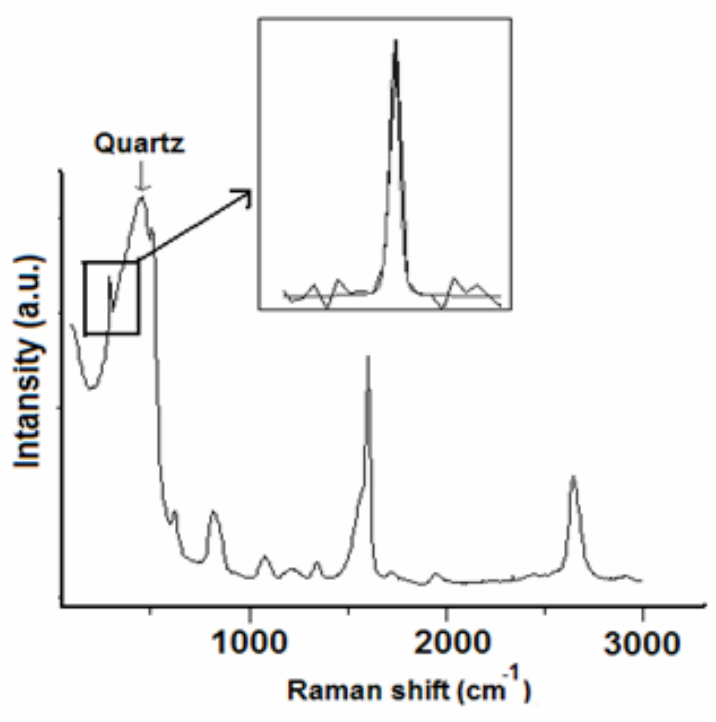

(b)

Fig. 6- (a) and (b) Raman spectrum of HiPco SWCNTs of SWCNTs/naphthalene composite samples of concentrations $\sim 1.17 \times 10^{-4} \mathrm{~mol} / \mathrm{L}$ and $\sim 1.46 \times 10^{-5} \mathrm{~mol} / \mathrm{L}$ respectively at $532 \mathrm{~nm}(2.33 \mathrm{eV})$ laser. Insets are the RBMs of corresponding samples after background correction and fittings.

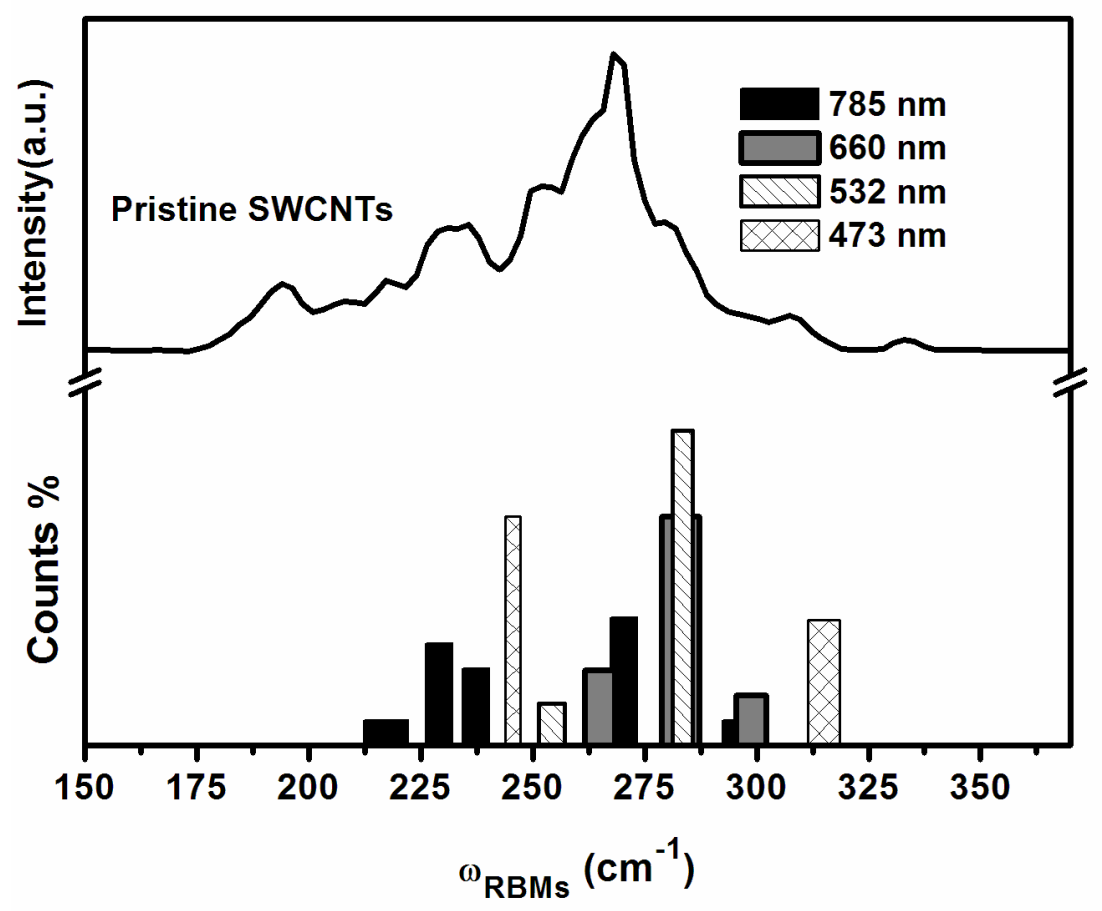


Fig. 7- RBM spectra as a function of percentage of counts of SWCNTs/naphthalene composite samples at concentration $\sim 1.46 \times 10^{-5} \mathrm{~mol} / \mathrm{L}$ at different laser energies.

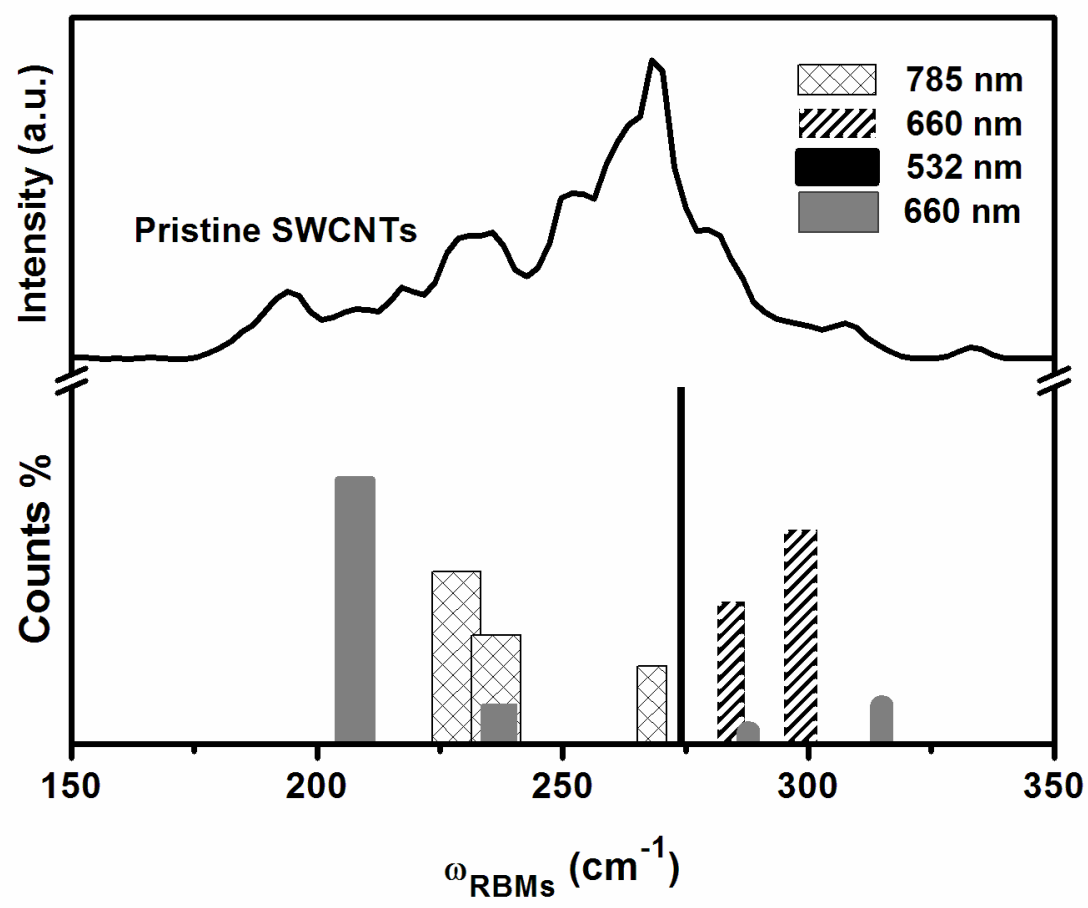

Fig. 8- A spectrum of RBMs frequencies as a function of percentage of counts of SWCNTs/biphenyl composite sample at concentration $\sim 3.05 \times 10^{-7} \mathrm{~mol} / \mathrm{L}$ at different laser energies.

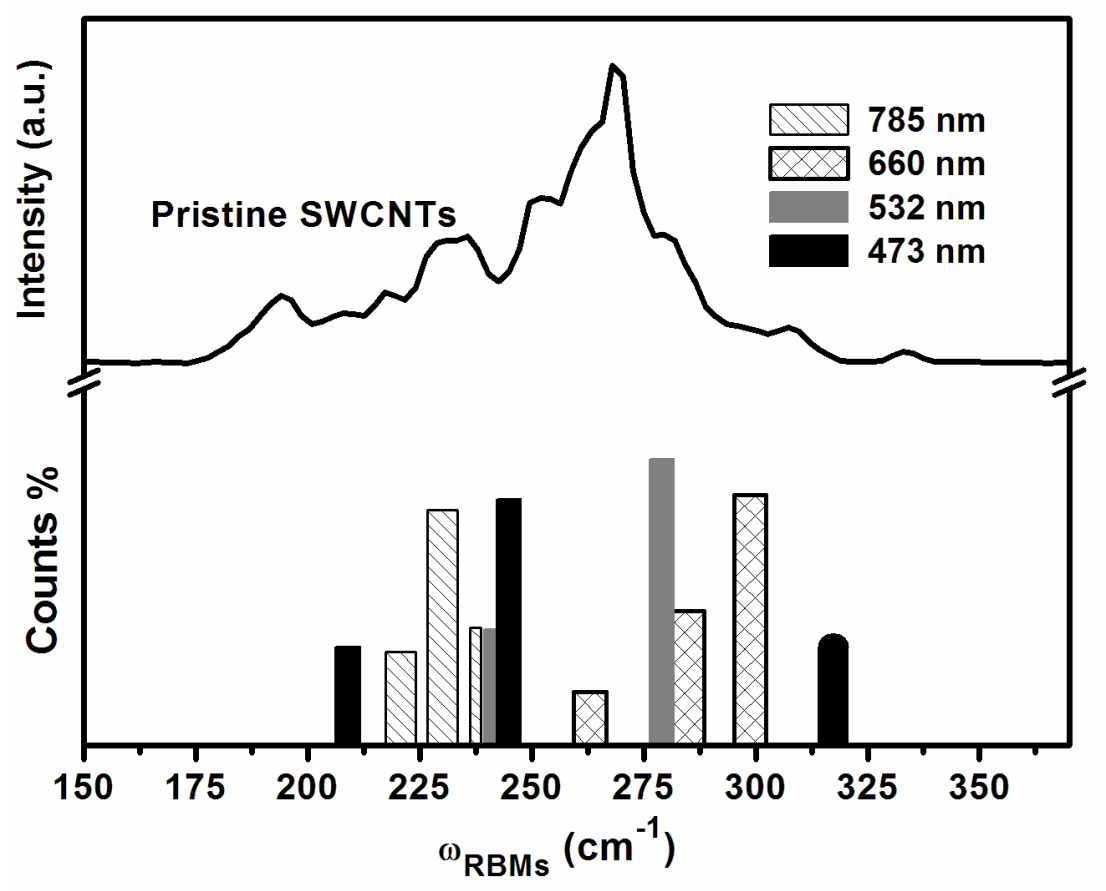


Fig. 9- A plot of RBMs shift as a function of percentage of counts of SWCNTs/tetracene composite sample at concentration $\sim 4.76 \times 10^{-9} \mathrm{~mol} / \mathrm{L}$ at different laser energies.

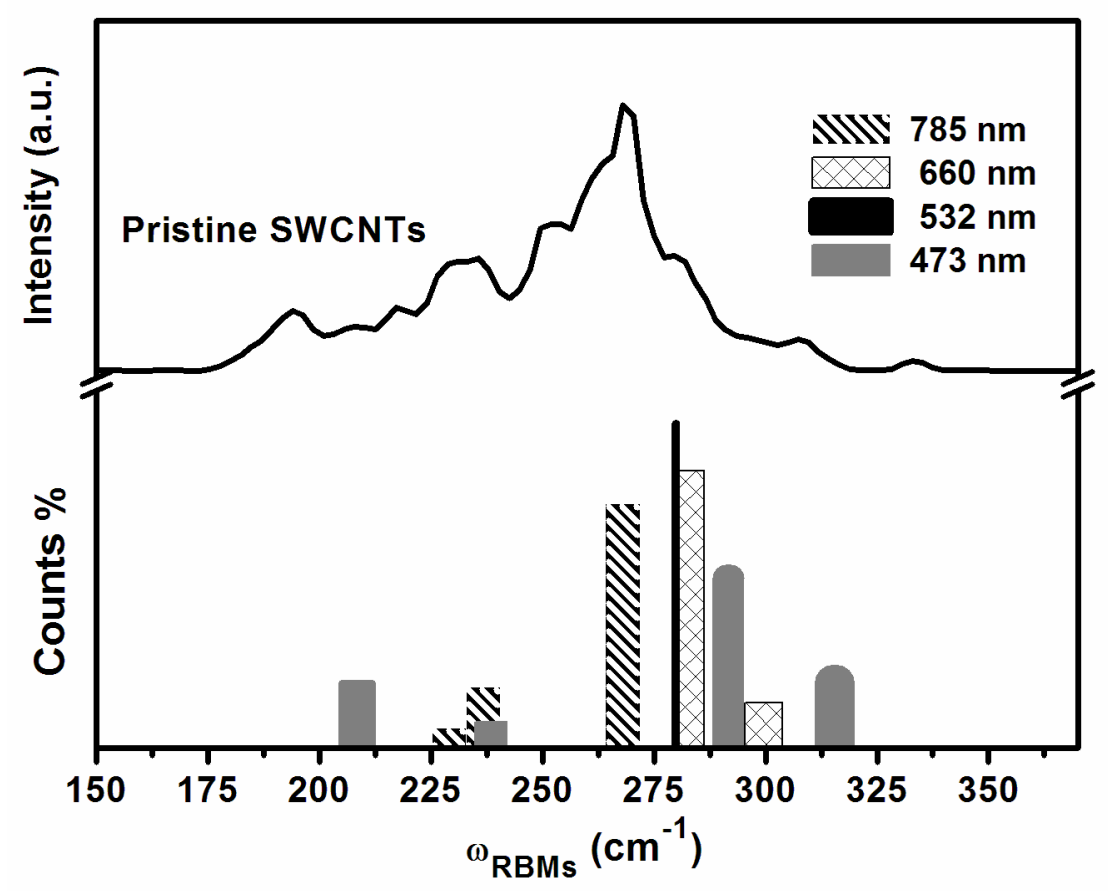

Fig. 10- Plot of RBMs shift as a function of percentage of counts of SWCNTs/pquaterphenyl composite at concentration $\sim 3.72 \times 10^{-11} \mathrm{~mol} / \mathrm{L}$ at different laser excitation energies. 